\title{
INFLUÊNCIA DO PROJETO ARQUITETÔNICO NA SEGURANÇA DO TRABALHO: PREVENÇÃO DE ACIDENTES EM OBRAS
}

\section{INFLUENCE OF THE ARCHITECTURAL DESIGN ON OCCUPATIONAL SAFETY: ACCIDENT PREVENTION ON CONSTRUCTIONS}

Karine Lopes Ferreira1 ${ }^{1}$, Bruno Márcio Agostini²

\section{RESUMO}

A construção civil está entre os principais setores industriais do país e também entre os que mais ocorrem acidentes do trabalho. Sendo assim, o presente trabalho trata da importância da abordagem da segurança do trabalho desde a fase do projeto arquitetônico, considerando essa uma das formas de se evitar os altíssimos índices de acidentes no referido setor. Desse modo, tem-se como objetivo elencar possíveis ações a serem tomados durante a fase de projeto, tendo em vista a fase de execução e manutenção para minimizar o índice de acidentes e doenças entre os trabalhadores do citado setor. A metodologia consistiu em revisão literária, trazendo dados quantitativos de acidentes do trabalho seguidos das causas de acidentes mais recorrentes, e na sequência, foram abordadas as possíveis práticas a serem adotadas durante o projeto para evitá-los. Os estudos consultados apontam que apesar de haver algumas dificuldades para se pensar em segurança de forma preventiva durante o projeto arquitetônico, é necessário que isso aconteça, dadas as possíveis consequências dos acidentes. Para isso, o projeto arquitetônico deve ser bem detalhado, de modo que seja possível antever quais processos serão realizados, a necessidade de mão obra especializada, maquinários a serem utilizados, a organização do canteiro de obras e outros aspectos abordados na presente pesquisa.

PALAVRAS-CHAVE: Construção civil. Acidente do trabalho. Planejamento de obra

\begin{abstract}
Civil construction is among the main industrial sectors in the country and among those with the most accidents at work. Thus, the present work deals with the importance of approaching work safety from the stage of architectural design, considering this one of the ways to avoid the very high accident rates in that sector. Thus, the objective is to list possible actions to be taken during a project phase with a view to an execution and maintenance phase to minimize the rate of accidents and illnesses among workers in the sector mentioned. The methodology consisted of a literary review, bringing quantitative data on occupational accidents, followed by the most recurrent causes of accidents, and subsequently, it was approached as possible practices to be adopted during the project to avoid it. The studies consulted indicate that although there are some difficulties in thinking about safety in a preventive way during the architectural design, it is necessary for this to happen, given the possible consequences of accidents. For this, the architectural design must be well detailed, so that it is possible to foresee which processes will be carried out, the need for specialized labor, machinery to be used, an organization of the construction site and other aspects valid in this research.
\end{abstract}

KEYWORDS: Civil Construction. Work accident. Construction planning

\footnotetext{
1 Graduação em Arquitetura e Urbanismo pela Universidade Federal de Juiz de Fora, especialização em Engenharia de Segurança do Trabalho pelo Instituto Federal do Sudeste de Minas Gerais - Campus São João del-Rei.

2 Graduação em Engenharia Civil (Ênfase em Estruturas) pela Universidade Federal de Juiz de Fora, Especialização em Engenharia de Segurança do Trabalho pela Universidade Federal de Juiz de Fora, Mestrado em Engenharia Civil (Estruturas) pela Universidade Federal do Rio de Janeiro, Doutorado em Engenharia Civil (Construção Metálica) pela Universidade Federal de Ouro Preto. Instituto Federal do Sudeste de Minas Gerais - Campus São João del-Rei
}

RECIMA21 - Ciências Exatas e da Terra, Sociais, da Saúde, Humanas e Engenharia/Tecnologia 


\section{RECIMA21 - REVISTA CIENTÍFICA MULTIDISCIPLINAR ISSN 2675-6218}

INFLUÊNCIA DO PROJETO ARQUITETÔNICO NA SEGURANÇA DO TRABALHO: PREVENÇÃO DE ACIDENTES EM OBRAS Karine Lopes Ferreira, Bruno Márcio Agostini

\section{INTRODUÇÃO}

O setor da construção civil está entre os segmentos com maiores índices de acidentes do trabalho e, por isso a temática da segurança e saúde do trabalhador nesse setor é comumente discutida. Somente no ano de $2018,5,13 \%$ do total de acidentes ocorridos no país correspondeu à construção civil (BRASIL, 2020a). No Brasil, o setor da construção é o primeiro segmento gerador de acidentes que resultam em incapacidade permanente; quando se trata de acidentes fatais, ocupa a segunda posição, perdendo apenas para os números do transporte terrestre; e em se tratando de afastamentos com mais de quinze dias, a atividade aparece em quinto lugar (ANAMT, 2019).

Como destaca a Associação Nacional de Medicina do Trabalho (ANMT) (ANAMT, 2019), a própria natureza das atividades dos canteiros de obras é perigosa, por isso faz-se necessária a adoção de medidas preventivas, como por exemplo:

- preparação do ambiente de trabalho de acordo com instruções normativas e treinamento dos funcionários para adoção das medidas de segurança;

- conhecer e seguir as Recomendações Técnicas de Procedimento (RTP) publicadas pela Fundacentro, que é uma instituição de pesquisa e estudos relativos à segurança, higiene e medicina do trabalho;

- adoção dos Equipamentos de Proteção Individual (EPI) como medidas complementares, salientando sempre aos funcionários que a prevenção dos acidentes não se restringe ao seu uso, sendo imprescindível que os demais cuidados sejam tomados.

Além desses pontos mencionados, é essencial o cumprimento dos preceitos das Normas Regulamentadoras (NR) que abarcam as atividades da construção civil, como:

- implantação da Comissão Interna de Prevenção de Acidentes (CIPA) ou conforme previsto na NR-05 (BRASIL, 2019);

- a elaboração e implementação do Programa de Controle Médico de Saúde Ocupacional (PCMSO), previsto na NR-07 (BRASIL, 2018), com a realização obrigatória dos exames médicos admissionais, periódicos, de retorno ao trabalho, mudança de risco ocupacional e demissionais para os trabalhadores, atendendo ao objetivo de promoção e preservação da saúde dos trabalhadores;

- cumprir exigências da NR-18: de acordo com a versão ainda em vigor (Portaria 261, de 18 de abril de 2018) (BRASIL, 2018c) é necessário elaborar o Programa de Condições e Meio Ambiente de Trabalho na Indústria da Construção (PCMAT) e o Programa de Prevenção de Riscos Ambientais (PPRA) da NR-9 (BRASIL, 2019b), que visa detectar os riscos e as condições inadequadas no ambiente laboral que afetam a saúde do trabalhador. Já a versão revisada da NR-18 (BRASIL, 2020b), com previsão para entrar em vigor a partir de 03/01/2022, exige o Programa de Gerenciamento de Riscos (PGR);

- o PGR (BRASIL, 2020b) dispõe sobre os requisitos gerais para as ações de prevenção e gerenciamento de riscos no ambiente de trabalho da construção civil, sendo um conjunto de procedimentos, técnicas de gestão, métodos de avaliação, registros e controles de monitoramento e avaliação de riscos que devem ser adotados pelas empresas. 


\section{RECIMA21 - REVISTA CIENTÍFICA MULTIDISCIPLINAR ISSN 2675-6218}

INFLUÊNCIA DO PROJETO ARQUITETÔNICO NA SEGURANÇA DO TRABALHO: PREVENÇÃO DE ACIDENTES EM OBRAS Karine Lopes Ferreira, Bruno Márcio Agostini

Com relação às principais causas desses elevados índices de acidentes, geralmente são apontadas falta de atenção ou instrução dos colaboradores, resistência ao uso de EPI e equipamentos obsoletos (CARVALHO, 2017). No entanto, pouco se relaciona tais acidentes e sua prevenção ao projeto arquitetônico. Esse aspecto pode ser indicativo de uma lacuna da adoção de medidas de segurança e saúde no momento da elaboração do projeto arquitetônico, o qual é a base para os demais projetos e de onde devem partir todas as diretrizes para a obra. No Brasil há poucos estudos que indicam essa relação entre projeto arquitetônico e segurança nas obras, o que vem a reforçar a importância deste presente estudo que busca detectar ações na fase projetual para minimizar os índices de acidentes nas obras.

Sendo assim, o presente trabalho teve como objetivo elencar possíveis ações, visando menor índice de acidentes e doenças entre os trabalhadores da construção civil, a serem tomadas desde o início da primeira etapa de uma obra: o projeto arquitetônico; e debater também como isso pode ser viável apesar das dificuldades existentes.

Como objetivos específicos teve-se:

- Realizar levantamento, com base em trabalhos já publicados, buscando identificar as principais causas de acidentes no setor da construção;

- Propor, com base nessas principais causas identificadas nos trabalhos publicados, possíveis soluções ou ações a serem consideradas ou tomadas na fase projetual, visando a redução de acidentes nas fases de execução ou manutenção.

Ressalta-se que não foi objetivo deste trabalho pesquisar sobre o processo do projeto arquitetônico na construção civil e sim exemplificar como pode ser viabilizada a abordagem da segurança no projeto, além de salientar sua necessidade.

\section{REFERENCIAL TEÓRICO}

\subsection{IDENTIFICAÇÃO DAS CAUSAS DE ACIDENTES NA CONSTRUÇÃO CIVIL}

Conforme Custódio e Schorr (2000) em 1995 passou a vigorar uma versão revisada da NR-18 em que foi implementado no item 18.32 um sistema estatístico de coleta e análise de dados sobre acidentes do trabalho na construção civil. Segundo esses mesmos autores, até então, sabia-se que esses índices eram altos, porém os dados não tinham o embasamento de estudos sistemáticos sobre as ocorrências e tampouco havia como acompanhar esses acidentes ao longo do tempo. Assim, foram incorporados dois anexos que permitiam o rastreamento desses acidentes e cálculo de indicadores para aprofundar sobre suas características (CUSTÓDIO; SCHORR, 2000).

Custódio e Schorr (2000) apresentaram dados de acidentes da construção civil entre os anos 1997 e 1999 com resultados indicando que:

- as partes do corpo mais lesadas eram os membros superiores, inferiores e tronco;

- acidentes ocorridos por impactos, quedas, aprisionamentos ou prensagem eram os mais expressivos;

- entre os principais agentes de lesão apareceram: peças metálicas ou vergalhões, pisos ou paredes, máquinas e equipamentos e ferramentas sem força motriz;

RECIMA21 - Ciências Exatas e da Terra, Sociais, da Saúde, Humanas e Engenharia/Tecnologia 


\section{RECIMA21 - REVISTA CIENTÍFICA MULTIDISCIPLINAR ISSN 2675-6218}

INFLUÊNCIA DO PROJETO ARQUITETÔNICO NA SEGURANÇA DO TRABALHO: PREVENÇÃO DE ACIDENTES EM OBRAS Karine Lopes Ferreira, Bruno Márcio Agostini

- as lesões mais consideráveis foram: contusões, cortes, fraturas, hematomas e irritação nos olhos.

Dados estatísticos mais recentes sinalizam que comparando com as informações da pesquisa de Custódio e Schorr (2000) é possível perceber que apesar do tempo transcorrido, da evolução tecnológica e da mecanização de alguns processos, o alto índice de acidentes e suas causas mais relevantes não tiveram mudança tão significativa.

Custódio e Schorr (2000), através da análise dos dados obtidos, identificaram prováveis subnotificações para os acidentes. Essa questão sinaliza que apesar da inserção dos instrumentos de coleta de dados na versão da NR 18 que passou a vigorar em 1995 ter representado grande avanço no segmento não foram suficientes para impedir as subnotificações. Ainda hoje é recorrente a observação de que os números registrados não correspondam à realidade.

Atualmente há outros instrumentos para o levantamento desses dados relativos à construção civil no Brasil, assim como os principais riscos e atividades que têm potencial de gerar danos à saúde do trabalhador, conforme apresenta-se na sequência.

\subsubsection{ANUÁRIO ESTATÍSTICO DE ACIDENTES DO TRABALHO (2018)}

Os dados a seguir foram retirados do Anuário Estatístico de Acidentes do Trabalho (AEAT) do ano de 2018. O AEAT são compilados de dados sobre acidentes do trabalho que permitem direcionar políticas de segurança relacionadas ao assunto. No AEAT são apresentados dados sobre os acidentes como: suas consequências, setores de atividades econômicas e em qual região ocorreram. Além desses, são apresentados também dados estatísticos sobre os acidentes conforme a Classificação Internacional de Doenças (CID) mais recorrentes em cada região do país. São contemplados ainda dados referentes à natureza de cada acidente, bem como se houve óbito, em quais setores de atividades econômicas mais trabalhadores se acidentam, entre outros.

No Quadro 1 são apresentados os quantitativos de acidentes relativos aos anos de 2016, 2017 e 2018. Esses quantitativos compreendem tanto os dados de acidentes que tiveram Comunicação de Acidente do Trabalho (CAT) registrada quanto os que não tiveram registro. A CAT é um formulário com várias partes, podendo ser preenchida de forma online pela empresa empregadora, pelo médico do trabalho, pelo próprio acidentado (ou seus dependentes), pelo sindicato da categoria, ou qualquer autoridade pública, e é a principal ferramenta estatística de acidente do trabalho da Previdência Social (BRASIL, 2021b). Seu objetivo é de levar ao conhecimento do Instituto Nacional do Seguro Social (INSS) o acidente ocorrido para assegurar alguns direitos ao trabalhador acidentado ou à sua família, em caso de óbito. O não preenchimento da CAT pode gerar multa ao empregador. Existem três modelos de CAT conforme indicado em Brasil (2021), a saber:

- inicial: deve ser aberta quando acontece o acidente ou doença ocupacional;

- reabertura: quando há agravamento de lesões decorrentes de acidente ou doença do trabalho; 
INFLUÊNCIA DO PROJETO ARQUITETÔNICO NA SEGURANÇA DO TRABALHO: PREVENÇÃO DE ACIDENTES EM OBRAS Karine Lopes Ferreira, Bruno Márcio Agostini

- óbito: é preenchida em caso de falecimento e vale apenas para os casos de óbito que ocorreram após o preenchimento da CAT inicial.

Os quantitativos correspondentes àqueles acidentes que não tiveram CAT Registrada, no Quadro 1, foram identificados pela nova forma de concessão de benefícios acidentários por meio de um dos possíveis nexos a seguir: Nexo Técnico Profissional/Trabalho, Nexo Técnico Epidemiológico Previdenciário (NTEP), Nexo Técnico por Doença Equiparada a Acidente do Trabalho ou Nexo Individual (BRASIL, 2020a).

Esses dados de acidentes sem CAT registrada são obtidos pelo levantamento da diferença entre o conjunto de benefícios acidentários concedidos pelo INSS com data de acidente no ano civil e o conjunto de benefícios acidentários concedidos com CAT vinculada, referente ao mesmo ano. Os dados de caracterização do acidentado são obtidos do Sistema Único de Benefícios (SUB) (BRASIL, 2020a).

Também no Quadro 1, os dados relativos aos acidentes típicos referem-se àqueles que ocorrem durante a execução do trabalho; os acidentes de trajeto são os que ocorrem no percurso da casa do empregado para o trabalho, e vice-versa; já os dados relacionados à "doença do trabalho" se referem a enfermidades desencadeadas em razão das condições em que o trabalho é realizado (BRASIL, 2021).

Quadro 1 - Quantitativo de Acidentes do Trabalho

\begin{tabular}{|c|c|c|c|}
\hline \multicolumn{4}{|c|}{ QUANTITATIVOS DE ACIDENTES DE TRABALHO } \\
\hline \multirow{6}{*}{ Com CAT registrada } & \multirow{3}{*}{ Acidente típico } & 2016 & 355.560 \\
\hline & & 2017 & 341.700 \\
\hline & & 2018 & 360.320 \\
\hline & \multirow{3}{*}{ Acidente de trajeto } & 2016 & 108.552 \\
\hline & & 2017 & 101.156 \\
\hline & & 2018 & 107.708 \\
\hline \multirow{6}{*}{ Com CAT registrada } & \multirow{3}{*}{ Doença do trabalho } & 2016 & 13.927 \\
\hline & & 2017 & 10.983 \\
\hline & & 2018 & 9.387 \\
\hline & \multirow{3}{*}{ Total } & 2016 & 478.039 \\
\hline & & 2017 & 453.839 \\
\hline & & 2018 & 477.415 \\
\hline \multirow{3}{*}{\multicolumn{2}{|c|}{ Sem CAT registrada }} & 2016 & 107.587 \\
\hline & & 2017 & 103.787 \\
\hline & & 2018 & 99.536 \\
\hline \multirow{3}{*}{\multicolumn{2}{|c|}{ TOTAL }} & 2016 & 585.626 \\
\hline & & 2017 & 557.626 \\
\hline & & 2018 & 576.951 \\
\hline
\end{tabular}

Fonte: BRASIL, (2020a) 


\section{RECIMA21 - REVISTA CIENTÍFICA MULTIDISCIPLINAR ISSN 2675-6218}

INFLUÊNCIA DO PROJETO ARQUITETÔNICO NA SEGURANÇA DO TRABALHO: PREVENÇÃo DE ACIDENTES EM OBRAS Karine Lopes Ferreira, Bruno Márcio Agostini

Já no Quadro 2 abaixo, são apresentados os números relativos apenas à construção civil de acordo com a Classificação Nacional de Atividades Econômicas (CNAE).

Quadro 2 - Acidentes relativos à construção civil

\begin{tabular}{|c|c|c|c|}
\hline \multicolumn{4}{|c|}{ ACIDENTES RELATIVOS À CONSTRUÇÃO CIVIL } \\
\hline \multirow{6}{*}{ Com CAT registrada } & \multirow{3}{*}{ Acidente típico } & 2016 & 25.622 \\
\hline & & 2017 & 20.895 \\
\hline & & 2018 & 21.032 \\
\hline & \multirow{3}{*}{ Doença do trabalho } & 2016 & 431 \\
\hline & & 2017 & 346 \\
\hline & & 2018 & 295 \\
\hline \multirow{3}{*}{ Com CAT registrada } & \multirow{3}{*}{ Total } & 2016 & 31.399 \\
\hline & & 2017 & 25.640 \\
\hline & & 2018 & 25.750 \\
\hline \multirow{3}{*}{\multicolumn{2}{|c|}{ Sem CAT registrada }} & 2016 & 5.760 \\
\hline & & 2017 & 4.684 \\
\hline & & 2018 & 3.862 \\
\hline \multirow{3}{*}{\multicolumn{2}{|c|}{ TOTAL }} & 2016 & 37.159 \\
\hline & & 2017 & 30.324 \\
\hline & & 2018 & 29.612 \\
\hline
\end{tabular}

Fonte: BRASIL, (2020a)

Em um comparativo entre os totais gerais (incluindo acidentes com e sem CAT registrada) dos dois quadros acima, é possível perceber que no ano de 2016 o número total de acidentes da construção civil foi correspondente à $6,35 \%$ de todos os casos; em 2017, 5,44\%; e no ano de 2018 , $5,13 \%$ do total de acidentes. Apesar destes números apresentarem redução, ainda são bastante expressivos, principalmente quando se leva em consideração a subnotificação de acidentes no segmento, muitas vezes decorrente da informalidade contratual dos trabalhadores, realidade bastante comum na construção civil.

A partir de estudos, estimou-se que se forem considerados os trabalhadores informais e os autônomos, o número de acidentes registrados na Previdência Social pode ser até sete vezes maior, se aproximando de 4 milhões de acidentados todos os anos (FUNDACENTRO apud RAMOS, 2020).

\subsubsection{PRINCIPAIS CAUSAS DE ACIDENTES NA CONSTRUÇÃO CIVIL}

Inicialmente, antes de discorrer sobre o assunto ao qual se propõe este tópico, faz-se necessário delimitar o entendimento que se dá aos termos "causas de acidentes" e "tipos de acidentes" empregados ao longo de todo o texto. Ocorre de ter autores que se referem como "causa" e outros que utilizam o termo "tipos", o que poderia dar margem a interpretações variadas, no entanto, como o presente trabalho é uma revisão literária, está sendo preservada a expressão e entendimento utilizados pelos autores referenciados, por isso as variações. 


\section{RECIMA21 - REVISTA CIENTÍFICA MULTIDISCIPLINAR ISSN 2675-6218}

INFLUÊNCIA DO PROJETO ARQUITETÔNICO NA SEGURANÇA DO TRABALHO: PREVENÇÃO DE ACIDENTES EM OBRAS Karine Lopes Ferreira, Bruno Márcio Agostini

Neste trabalho, o termo "causas", mais recorrente, está sendo tratado como algo mais amplo, não sendo o fator básico de origem do acidente, e que pode abarcar nas suas entrelinhas sentidos mais específicos, que, no entanto, não é o objetivo desta pesquisa esmiuçá-los. Como por exemplo: foi muito apontada a "causa queda", no entanto, sabe-se que há várias razões que podem ocasionar quedas no canteiro de obras, tais como: queda em razão de desnível; em razão de tropeço em equipamento ou material; entre outros. Sabe-se ainda que caso aconteça uma queda, várias são as suas consequências que podem desencadear alguma doença no acidentado ou até mesmo provocar seu óbito. Feito esse esclarecimento, a seguir tem-se a continuidade da discussão proposta pelo trabalho.

Conforme apontam Silveira et al. (2015), o setor da construção civil atinge as camadas pobres da população masculina, com baixo índice de escolaridade e que por vezes desconhece os seus direitos enquanto profissionais, o que os leva a admissão da culpa dos acidentes, evitando procurar o atendimento à saúde, e quando o fazem, omitem a causa do acidente. Soma-se a isso a alta rotatividade de mão de obra nas empresas, e não raro a insuficiência dos treinamentos e qualificação profissional para os funcionários, o que muitas vezes reflete em diminuição da produtividade e da qualidade de vida do profissional.

Enquanto no Brasil, a taxa de mortalidade no trabalho é de 5,21 mortes para cada 100 mil vínculos, na construção civil, esse valor atinge 11,76 casos para cada grupo de 100 mil (ANAMT, 2019). Entre os principais tipos estão: impactos com objetos, quedas em altura, choques elétricos e soterramento ou desmoronamento (ANAMT, 2019). Há também quedas de materiais, ausência de sinalização adequada e conhecimento insuficiente dos materiais e processos a serem desenvolvidos por parte dos trabalhadores.

De acordo com Silveira et al. (2005), em uma pesquisa realizada em hospital da cidade de Ribeirão Preto, estado de São Paulo, cujo objetivo foi investigar o número de trabalhadores acidentados e sua possível relação com as atividades desenvolvidas por eles na construção civil, foram investigados 6.122 prontuários, e deste total $10,09 \%$, ou seja, 618 referiam-se a pacientes/trabalhadores com acidente do trabalho. Referente aos 618 acidentados do trabalho, 150 deles eram de trabalhadores da construção civil, o que representa um percentual de $24,27 \%$.

Segundo Silveira et al. (2005), as quedas de altura apareceram entre as principais causas de acidentes, em $37,7 \%$ dos casos. A ocorrência dessas quedas é comum em beiras de lajes, escadas, muros e andaimes, possivelmente por não utilização dos EPI; realização de atividades de maneira perigosa, além do uso de andaimes e demais equipamentos muitas vezes sem revisão (SILVEIRA et al., 2005). Além da queda em altura ser a causa mais recorrente e crítica, é a responsável por muitos casos serem fatais (SOUSA; CAMPOS, 2017).

Através de informações fornecidos pela Occupational Safety and Health Administration (OSHA) que incluíam todas as investigações da organização a respeito de mortes e feridos graves nos Estados Unidos de janeiro de 1990 a outubro de 2001, Hinze e Huang (2003) apud Sousa e Campos, (2017) realizaram um estudo com o objetivo de determinar as causas dos acidentes relativos à queda na construção. Os resultados apontaram motivos relacionados a determinados erros 
INFLUÊNCIA DO PROJETO ARQUITETÔNICO NA SEGURANÇA DO TRABALHO: PREVENÇÃO DE ACIDENTES EM OBRAS Karine Lopes Ferreira, Bruno Márcio Agostini

humanos. Nas causas que envolviam telhados, apareceram com maior representatividade $(33,3 \%)$ os motivos relacionados ao erro de julgamento dos trabalhadores sobre situações perigosas; em seguida, $13,5 \%$ dos casos foram associados a insuficiência ou falta de EPI e por fim, 11,5\% foram causados por dispositivos de segurança retirados ou inoperantes (HINZE; HUANG, 2003 apud SOUSA; CAMPOS, 2017).

Em outra pesquisa Souza e Campos (2017) observaram a grande relação das quedas a fatores de layout, que envolvem a superfície de trabalho ou condições de layout da instalação; situações de escorregamento de telhados inclinados e quedas nas aberturas do chão ou em superfícies de andaimes também foram motivos recorrentes. Essas mesmas autoras ressaltaram ainda que equipamentos inadequados de prevenção de queda em edifícios e/ou estruturas e suas falhas causaram acidentes de queda. Desse modo, os dados obtidos por Souza e Campos (2017) direcionam para a necessidade de cumular esforços em projetos de layout, logística, e condições do ambiente de trabalho como medidas essenciais que busquem prevenir esses acidentes.

Uma pesquisa realizada por Maia (2008) apud Souza e Campos (2017) reforçou o que foi mencionado sobre os acidentes envolvendo quedas. Essa pesquisa realizada com base em dados estatísticos de acidentes fatais, entre 2002 e 2006 ocorridos no estado de Pernambuco/Brasil revelou que $40,5 \%$ dos acidentes fatais estavam relacionados a quedas de diferença de nível e ocorriam principalmente em serviços realizados na fase de manutenção.

Retomando agora às demais causas apontadas na pesquisa com os prontuários hospitalares, Silveira et al. (2005) apontaram que o contato com ferramentas, máquinas e aparelhos, muitas vezes utilizados incorretamente e nem sempre com a devida manutenção, foram responsáveis por $16 \%$ dos índices de acidentes. Foram identificados ainda os acidentes de trajeto, ocorridos por diversos meios (12,7\%); acidentes com impacto de objetos representaram $11,3 \%$ do total, sendo lançados tanto por outros colegas quanto em queda, muitas vezes por falta de cuidado.

O Quadro 3 apresenta todas as causas de acidentes de trabalho identificadas por Silveira et al. (2005) e sua respectiva porcentagem de incidência nesta pesquisa com os prontuários hospitalares, especificamente nos 150 prontuários que se referem à construção civil:

Quadro 3 - Principais causas de acidentes na Construção Civil

\begin{tabular}{|c|c|}
\hline CAUSA/OBJETO DE ACIDENTE DO TRABALHO & PORCENTAGEM (\%) \\
\hline Quedas & 37,3 \\
\hline Contatos com ferramentas, máquinas e aparelhos & 16 \\
\hline Acidente de trajeto & 12,7 \\
\hline Impacto por objeto & 11,3 \\
\hline Corpo estranho & 8,0 \\
\hline Agressão & 4,0 \\
\hline Contato com vidro & 2,7 \\
\hline Exposição à corrente elétrica & 2,7 \\
\hline Contato com fontes de calor & 1,3 \\
\hline Outros & 4,0 \\
\hline TOTAL & 100,0 \\
\hline
\end{tabular}

Fonte: adaptado de Silveira et al., (2005) 
Quanto às partes do corpo lesadas, 30,7\% dos trabalhadores tiveram seus membros superiores atingidos, por serem mais diretamente envolvidos e expostos; $24,0 \%$ de ferimentos na cabeça, mais especificamente os olhos; $19,3 \%$ dos acidentes afetaram múltiplas partes; $16 \%$ tiveram os membros inferiores afetados; $8,0 \%$ apresentaram lesão no tórax; e em apenas $2,0 \%$ dos prontuários registrados não foram identificadas lesões (SILVEIRA et al., 2005).

Nesta mesma pesquisa, Silveira et al.(2005) apontaram como fatores causadores e agravantes de acidentes nas obras: a desorganização do canteiro com equipamentos pontiagudos e escombros espalhados; falta de dispositivos de proteção para o acesso à obra; mesmo meio de transporte utilizado para pessoas e cargas; o uso de EPI muitas vezes restrito apenas a capacetes e luvas, negligenciando o uso dos demais equipamentos como protetores auriculares e faciais, cintos de segurança e os sapatos especiais.

Em outro trabalho, os autores Mazon e Savi (2013) realizaram uma pesquisa em uma construtora da cidade de Criciúma, entre janeiro de 2012 a setembro de 2013, com o objetivo de levantar dados estatísticos de acidentes na cidade para buscar uma redução dos números elevados. Nessa pesquisa, as causas dos acidentes foram tomadas como o que aparecia descrito na CAT.

Os motivos identificados por Mazon e Savi (2013) foram: queda, lesão nos membros, queda de objeto, corte e acidentes de trajeto. As partes do corpo mais atingidas foram: cabeça, membros superiores, membros inferiores e tronco. E os objetos causadores dos acidentes foram divididos em sete categorias, a seguir: escada, serras em geral ou máquinas, blocos, formas em geral ou andaimes, materiais de alta temperatura ou nocivos, bicicleta/moto e tábua/barrote. A faixa etária que apresentou o maior número de acidentes foi acima dos 50 anos, e foi tomado com indicativo de que com o avanço da idade, o profissional tende a ser mais experiente ao mesmo tempo em que se torna mais resistente ao correto uso do EPI, já tem hábitos de trabalho mais definidos e consequentemente menos preocupação com as atividades, podendo gerar descuido e levar aos acidentes (MAZON; SAVI, 2013).

Souza e Campos (2017) elencaram as principais causas dos acidentes no setor da construção e apesar de serem bastante variadas, verificou-se que a maior parte, cerca de $70 \%$, estavam relacionadas a fatores de erros humanos. A listagem dessas causas foi feita a partir da frequência com que foram citadas em outros onze artigos selecionados pelas autoras para o trabalho de acordo com a metodologia utilizada, e a partir disso, foi realizado o agrupamento das dezenove principais causas de acidentes no setor em cinco grupos, como mostra o Quadro 4 a seguir:

Quadro 4 - Principais Causas de Acidentes na Construção Civil (continua)

\begin{tabular}{|c|l|}
\hline \multicolumn{2}{|c|}{ PRINCIPAIS CAUSAS DE ACIDENTES NA CONSTRUÇÃO CIVIL } \\
\hline \multirow{4}{*}{$\begin{array}{c}\text { Equipe de } \\
\text { trabalhadores }\end{array}$} & demandas de tarefas em excesso \\
\cline { 2 - 2 } & falta de capacitação, conhecimento e habilidades \\
\cline { 2 - 2 } & $\begin{array}{l}\text { julgamento errôneo da situação de perigo } \\
\text { declínio relacionado às idades das capacidades cognitivas, comportamento e estado } \\
\text { psicológico }\end{array}$ \\
\cline { 2 - 2 } & saúde/fadiga do trabalhador \\
\cline { 2 - 2 } & posição operacional não apropriada para a tarefa \\
\hline
\end{tabular}




\section{RECIMA21 - REVISTA CIENTÍFICA MULTIDISCIPLINAR} ISSN 2675-6218

INFLUÊNCIA DO PROJETO ARQUITETÔNICO NA SEGURANÇA DO TRABALHO: PREVENÇÃO DE ACIDENTES EM OBRAS Karine Lopes Ferreira, Bruno Márcio Agostini

Quadro 4 - Principais Causas de Acidentes na Construção Civil (conclusão)

\begin{tabular}{|c|l|}
\hline \multirow{4}{*}{$\begin{array}{c}\text { Ambiente de } \\
\text { trabalho }\end{array}$} & $\begin{array}{l}\text { fatores ambientais que envolvem a superfície de trabalho ou condições de layout da } \\
\text { instalação }\end{array}$ \\
\cline { 2 - 3 } & ambiente de trabalho (iluminação / ruído / quente / frio / molhado) \\
\cline { 2 - 3 } & insuficiência ou falta de programa de limpeza \\
\hline \multirow{4}{*}{ Materiais } & estabilidade dos materiais \\
\cline { 2 - 3 } & condição dos materiais \\
\cline { 2 - 3 } & utilização dos materiais (procedimento e manuseio) \\
\hline \multirow{4}{*}{ Equipamentos } & insuficiência de EPI ou falta de proteção vestuário de trabalho e equipamentos \\
\cline { 2 - 3 } & falta de equipamento / método de manipulação de materiais \\
\cline { 2 - 3 } & dispositivos de segurança removidos ou inoperantes \\
\cline { 2 - 3 } & equipamentos inadequados de prevenção de queda em altura \\
\hline \multirow{2}{*}{ Influências } & falhas originadas durante o processo de planejamento e projeto \\
\cline { 2 - 3 } & ausência de gerenciamento de risco \\
\cline { 2 - 2 } & ausência / insuficiência de supervisão \\
\hline
\end{tabular}

Fonte: adaptado de Sousa e Campos, (2017)

Observando o quadro acima, percebe-se que o grupo que traz o maior número de tipos de causas de acidentes é o "equipe de trabalhadores", o que sugere maior investimento em treinamentos, gerenciamento, fiscalização e gestão de recursos humanos, abordando a prevenção dos acidentes nos fatores causais, o que resulta na contribuição para maior eficiência dos processos (SOUSA; CAMPOS, 2017).

Quando as causas indicadas no Quadro 4 são agrupadas em ordem de relevância, o item referente a "falhas originadas durante o processo de planejamento e projeto" do grupo "influências originárias" aparece em segunda posição, ficando atrás somente do item de "insuficiência de EPI ou falta de proteção vestuário de trabalho e equipamentos" do grupo de "equipamentos" o que demonstra grande necessidade de investimentos em programas e estudos de gerenciamento de risco e projetos, planejamento e gestão (SOUSA; CAMPOS, 2017). Diante da ordem de relevância obtida por Sousa e Campos (2017) tem-se indicativo da existência de vínculo entre projetos e a ocorrência de acidentes na obra, sinalizando novamente para a necessidade de prevenção através do projeto arquitetônico orientado para a segurança através das soluções propostas, cumprimento de normas e indicação de organização do canteiro.

\subsection{INFLUÊNCIA DO PROJETO ARQUITETÔNICO NA SEGURANÇA DO CANTEIRO DE OBRAS}

De acordo com um estudo realizado no Reino Unido por Manu et al. (2014), o alto índice de acidentes na construção civil levou à necessidade de identificar e implementar medidas que pudessem reduzir as taxas de acidentes no setor. A partir de então, identificou-se que a prevenção dos acidentes deveria iniciar na fase de pré construção. Nessa fase, de acordo com esse estudo, os

RECIMA21 - Ciências Exatas e da Terra, Sociais, da Saúde, Humanas e Engenharia/Tecnologia 


\section{RECIMA21 - REVISTA CIENTÍFICA MULTIDISCIPLINAR ISSN 2675-6218}

INFLUÊNCIA DO PROJETO ARQUITETÔNICO NA SEGURANÇA DO TRABALHO: PREVENÇÃO DE ACIDENTES EM OBRAS Karine Lopes Ferreira, Bruno Márcio Agostini

profissionais responsáveis pelos projetos e sua gestão, através de suas decisões, têm a capacidade de influenciar a saúde e segurança nos canteiros de obras, uma vez que a ocorrência desses acidentes apresenta relação direta com o projeto, sua complexidade e duração da execução.

Nesse mesmo estudo, Manu et al. (2014) também apontaram o grau do potencial para influenciar a ocorrência dos acidentes, por exemplo: a execução de um projeto com o cronograma justo apresenta alto potencial, enquanto um projeto com a duração adequada, apresenta grau moderado. Da mesma forma, um projeto complexo apresenta alto potencial, enquanto um projeto simples apresenta grau moderado. Outro ponto interessante apresentado nesse mesmo estudo é que apesar dos benefícios da construção pré-moldada, quando considerado o potencial de influenciar a ocorrência de acidentes, ao contrário do que poderia ser esperado, esse método não apresenta potencial reduzido em relação ao método tradicional de construção, ambos apresentam potencial moderado (MANU et al., 2014).

Diante do exposto e da possibilidade de aumento da segurança e saúde na construção durante a fase de projeto, é imperativo, de acordo com Smallwood (2005), que os aspectos de Saúde e Segurança do Trabalho (SST) sejam considerados desde o início do exercício projetual. Dessa forma, busca-se não incluir elementos que exijam procedimentos ou materiais perigosos, como por exemplo: materiais pesados que ocasionam problemas de manuseio ou que exijam métodos de fixação que demandem dos funcionários trabalhar em posições desconfortáveis, com movimentos repetitivos e/ou usar demasiadamente a força corporal. Também, conforme Smallwood (2005), o projeto deve estar integrado à execução da obra e às atividades de gestão, com quantitativos e cronogramas adequados, mão de obra capacitada, disponibilização para os clientes e outros profissionais de todos os dados e relatórios relevantes do projeto, e disponibilização de informações sobre quaisquer ocorrências que exijam cuidados especiais para a execução segura.

O National Institute for Occupational Safety And Health (NIOSH) define o conceito de Prevenção Através de Projeto (PAP) ou Prevention Through Design (PTD), como é conhecido internacionalmente, como o direcionamento para evitar ou reduzir lesões, doenças e fatalidades ocupacionais, através da inserção de considerações de prevenção em todos os projetos que possam atingir os trabalhadores. Para isso, deve-se eliminar perigos e controlar riscos para os colaboradores, incluir no projeto a modernização das instalações, estruturas, ferramentas, equipamentos, máquinas, produtos, substâncias e processos de trabalho. Além desses pontos, deve-se melhorar o ambiente de trabalho através da inclusão de métodos de prevenção. Desse modo, é possível aumentar a produtividade e diminuir os riscos e custos das atividades ( $\mathrm{NIOSH}, 2013$ ).

Entre as funções do projeto está o potencial de minimizar problemas futuros, evitar retrabalhos, custos não previstos, danos ao meio ambiente, acidentes de trabalho, além de poder ser utilizado como ferramenta de melhoria e qualidade da produtividade. Silva (2009) afirmou que a inserção das medidas de SST na fase de concepção do projeto tem a capacidade de aumentar o potencial no controle de riscos de acidentes, exigindo poucos recursos necessários: conhecimentos técnicos de SST e a integração da equipe envolvida. Para isso, de acordo com Silva (2009), é 


\section{RECIMA21 - REVISTA CIENTÍFICA MULTIDISCIPLINAR ISSN 2675-6218}

INFLUÊNCIA DO PROJETO ARQUITETÔNICO NA SEGURANÇA DO TRABALHO: PREVENÇÃO DE ACIDENTES EM OBRAS Karine Lopes Ferreira, Bruno Márcio Agostini

necessária a aproximação do profissional responsável pelo projeto arquitetônico com a temática da segurança ainda durante a graduação.

\subsection{DIFICULDADES DE ABORDAGEM DE SEGURANÇA DESDE A FASE PROJETUAL}

Para que ocorra a abordagem antecipada da segurança, faz-se necessário inicialmente promover a aproximação do profissional responsável pelo projeto arquitetônico com o canteiro de obras desde a fase projetual, para que seja projetado já pensando na execução e na forma como serão dispostos os elementos e componentes necessários dentro do canteiro de obras (BASTO; VASCONCELOS; BARDOKÉBAS, 2016). Hinze e Gambatese (1996) apud Saurin (2005) também abordaram essa questão ao afirmar que é necessário que haja o enfrentamento de alguns desafios que dificultam a integração da segurança com o desenvolvimento de projeto, como: o pouco conhecimento do projetista em assuntos de segurança, o que ocorre geralmente em decorrência da falta de componentes dessa temática na grade curricular, e a tentativa de evitar responsabilidades legais sobre acidentes de trabalho.

Segundo Saurin (2005) entende-se que, de forma mais imediata, essas questões podem ser trabalhadas, como por exemplo, com a avaliação dos riscos juntamente a profissionais com experiência em gestão de segurança na área da construção civil. $O$ autor aponta que com a inclusão nos contratos de prestações de serviços destas novas competências que envolvem a segurança do trabalho, os exigentes critérios de custos e prazos impostos pelos clientes, bem como a desvalorização desta atribuição profissional do projetista podem ser evitados.

Além das dificuldades mencionadas anteriormente, de acordo com Saurin (2005), há ainda outros empecilhos para que se considerem os requisitos de segurança nos projetos, como:

- ausência de feedback aos projetistas acerca de riscos identificados;

- critério de menor preço em licitações do setor público;

- falta de estimativa de custos com manutenção da edificação contribuindo para a negligência da segurança nessas atividades;

- falta da aplicação do código de defesa do consumidor, gerando sub registro dos problemas de segurança durante a manutenção;

- custo mais elevado de alternativas de projeto que podem favorecer a construtibilidade;

- falta de clara identificação dos requisitos dos clientes externos e internos nos estágios iniciais do desenvolvimento do projeto, o que gera retrabalho em excesso nas soluções criadas, independentemente de serem ou não relacionadas à segurança.

Por essas dificuldades, de acordo com Saurin (2005) torna-se comum que os projetistas considerem os requisitos de facilidade de execução em seus projetos de maneira informal, ocorrendo que mesmo quando identificam possíveis riscos de acidentes, raramente comunicam formalmente ao cliente e construtor. Assim, tem-se o retardo da identificação e do combate desses riscos na origem o que consequentemente dificulta o aproveitamento desse conhecimento adquirido em futuros projetos e obras, já que não são documentados em memoriais e relatórios (SAURIN, 2005). 


\section{RECIMA21 - REVISTA CIENTÍFICA MULTIDISCIPLINAR ISSN 2675-6218}

INFLUÊNCIA DO PROJETO ARQUITETÔNICO NA SEGURANÇA DO TRABALHO: PREVENÇÃO DE ACIDENTES EM OBRAS Karine Lopes Ferreira, Bruno Márcio Agostini

Baker et al. (1999) apud SAURIN, (2005) sugeriram, para que ocorra a implementação prática da segurança ao projeto, que algumas etapas sejam seguidas na seguinte ordem:

- Identificação dos riscos: etapa em que são captados os requisitos dos clientes e utilizadas técnicas para identificar os riscos, como por exemplo listas de verificação, reunião entre projetista e equipe de produção, e prototipagem;

- Avaliação: após ter sido feita a identificação, nesta etapa é realizada a estimativa da severidade e probabilidade de cada risco identificado. Nesta fase, porém, pode ser que não ocorra a compreensão detalhada de cada risco, caso os métodos executivos não estejam previamente definidos;

- Resposta: etapa em que são implementadas medidas no projeto para reduzir, conter ou eliminar os riscos identificados anteriormente;

- Controle dos riscos: ocorre durante a execução, objetivando implementar as medidas especificadas no projeto.

Desse modo, havendo o já citado entrosamento do projetista com a temática da segurança, é possível que o profissional tenha maior visualização das consequências que as decisões tomadas podem gerar na construtibilidade.

No contexto da construção civil, o conceito da construtibilidade é tido como o bom uso dos conhecimentos de obras e a experiência em planejamento, engenharia, suprimentos e operações de campo para atingir os objetivos do projeto baseados na necessidade de cada um e em cada fase do seu processo de liberação; é tido como a facilidade de construir (YOGUI, s.d.).

Assim, o conceito de construtibilidade reforça a integração do projeto com a construção; do arquiteto com os demais profissionais envolvidos no canteiro; e do responsável pela segurança do trabalho com o construtor, o que facilita o esclarecimento in loco das informações necessárias e permite conciliar as etapas de criação e execução com segurança e qualidade. O conceito reforça também a adequada sequência das operações, além da organização e bom arranjo do canteiro, já que esses fatores contribuem para o aumento da segurança nas obras, uma vez que as atividades fluem de maneira ordenada, evitando interrupções e recomeços desnecessários, desperdícios e improvisos, sempre considerando os profissionais que executarão esses projetos.

De acordo com Saurin (2005), apesar de ser esperado que a iniciativa de considerar a segurança no projeto parta do projetista, é necessário que haja discussão deste com os clientes e a construtora, já que raramente estes dois últimos entes levantam este tipo de demanda. A intenção dessa interação é que tão cedo quanto possível sejam aprovadas soluções propostas, para que não ocorra esquivamento das partes envolvidas (SAURIN, 2005).

Cabe ressaltar que a segurança deve ser abordada por todos os projetistas como demanda intrínseca de seus respectivos projetos, não apenas pelo profissional responsável pelo projeto arquitetônico. Essa abordagem deve ser feita o quanto antes, evitando procrastiná-la para as reuniões de compatibilização dos projetos, uma vez que esses encontros já costumam ser longos e exaustivos para os envolvidos que levam várias outras demandas como prioritárias (SAURIN, 2005). 


\section{RECIMA21 - REVISTA CIENTÍFICA MULTIDISCIPLINAR ISSN 2675-6218}

INFLUÊNCIA DO PROJETO ARQUITETÔNICO NA SEGURANÇA DO TRABALHO: PREVENÇÃO DE ACIDENTES EM OBRAS Karine Lopes Ferreira, Bruno Márcio Agostini

\section{METODOLOGIA}

A metodologia de desenvolvimento do trabalho se baseou em revisão literária, que consiste na reunião de informações de pesquisas e discussões publicadas por outros autores sobre o tema abordado, e que auxiliassem a atingir os objetivos propostos para este trabalho.

As pesquisas ocorreram entre os meses de março de 2020 a agosto de 2021. A busca por publicações que pudessem ser relevantes ocorreu de maneira ampla, ou seja, não foram utilizadas palavras-chave ou plataformas de pesquisas específicas para não restringir trabalhos que porventura pudessem contribuir, mas não constariam nesses meios. Também não foi restrito o intervalo de tempo/ano de publicação para que as pesquisas pudessem ser consideradas neste trabalho. Essa linha de ação foi adotada principalmente diante da escassez de referências sobre o assunto, especialmente publicações nacionais.

RESULTADOS E DISCUSSÃO

Com base nos resultados obtidos pelos autores citados anteriormente, as principais causas que resultam em acidentes na construção civil foram elencadas:

- quedas;

- utilização inadequado de equipamentos, máquinas e aparelhos;

- impactos de objetos;

- condições inadequadas do ambiente de trabalho como desorganização do canteiro de obras;

- falta de dispositivos de proteção ao acesso da obra e mesmo meio de transporte utilizado para pessoas e cargas;

- uso inadequado do EPI;

- demandas em excesso aos trabalhadores e atividades que exijam excesso de esforço físico.

Dessa forma, em se tratando de prevenção, por serem mais recorrentes, as causas descritas anteriormente, foram consideradas como as que requerem maior atenção com indicação de formas de prevenção pelo projeto; através de especificação ou notas de orientação que indiquem como deve ser procedida a execução.

Analisando conjuntamente as pesquisas apresentadas é possível identificar que é de consenso entre os autores citados que acidentes provocados por quedas sejam os mais recorrentes, e os motivos que os ocasionam são variados, como descrito a seguir: erro humano, erro de julgamento quanto ao perigo; mal uso, falha ou não utilização de EPI, dispositivo de segurança inoperante; desorganização nos canteiros de obras, condições indevidas de layout das instalações

Cabe aqui uma observação sobre as recorrentes causas mencionadas "erro humano" ou "erro de julgamento quanto ao perigo": pelo contexto apresentado nas pesquisas que subsidiaram este trabalho, é possível perceber que essas causas são geralmente consideradas de maneira ampla. Assim, é válido ressaltar que possivelmente estejam refletindo em alguma escala problemas elementares presentes na administração das empresas atuantes nas obras. 


\section{RECIMA21 - REVISTA CIENTÍFICA MULTIDISCIPLINAR ISSN 2675-6218}

INFLUÊNCIA DO PROJETO ARQUITETÔNICO NA SEGURANÇA DO TRABALHO: PREVENÇÃO DE ACIDENTES EM OBRAS Karine Lopes Ferreira, Bruno Márcio Agostini

Muitas vezes a falta de treinamentos, de programas que conscientizem os funcionários sobre segurança, falta de investimentos nessa área, alta rotatividade da mão obra, altas exigências de prazo e produtividade, entre outros fatores, vão refletir de forma mais grave no trabalhador que atua na ponta, diretamente envolvido na execução das edificações e posteriormente na sua manutenção. Desse modo, é importante que o olhar seja crítico a fim de perceber as entrelinhas que podem estar sendo abarcadas, e que também seja sensível a fim de não culpabilizar demasiadamente apenas o trabalhador final.

\subsection{AÇÕES NA ETAPA DE PROJETO PARA ATENUAR RISCOS}

A partir dos dados levantados nas seções anteriores, foram identificados aspectos que demandam atenção dos envolvidos nas atividades da construção civil, a fim de evitar acidentes e danos à saúde dos trabalhadores. Trata-se do estabelecimento de ações que envolvem desde a necessária organização dos canteiros de obras, com o adequado armazenamento de ferramentas e equipamentos, até o cumprimento do que foi previamente planejado em projeto, seguindo 0 cronograma de modo a evitar intercorrências e improvisos ao longo da construção. É na fase de concepção que se verifica a viabilidade da obra, e quando as decisões podem e devem ser tomadas visando otimizar o produto final em vários aspectos, como: do ponto de vista financeiro, do seu desempenho e dos processos produtivos.

Dessa forma, quando as preocupações com a segurança surgem desde a fase projetual, a prevenção de riscos tende a se tornar mais efetiva, uma vez que há o potencial de eliminar ou reduzir perigos na origem. Essa é a grande vantagem da abordagem antecipada da segurança, e esta parece ser umas das alternativas mais eficazes. Nesse contexto, é válido ressaltar que não necessariamente precisarão ser modificadas as decisões de projeto caso algum risco seja identificado, basta que se realize o planejamento antecipado com previsão de métodos seguros para a execução (SAURIN, 2005). Saurin (2005) sugeriu a adoção de listas de verificação como uma forma de documentar as demandas que devem ser discutidas e consideradas pelos projetistas.

Como resposta às causas identificadas anteriormente, serão apresentados a seguir alguns pontos que devem ser considerados. É possível observar que alguns tópicos, além de atenderem às necessidades de segurança da obra durante a construção, também são importantes para a fase de utilização e manutenção da edificação, para evitar improvisos.

\subsubsection{QUEDAS}

Segundo os autores citados no presente trabalho: Custódio e Schorr (2000); Souza et al.; (2005); Mazon e Savi (2013); e Sousa e Campos (2017); a queda é causa recorrente apontada nos acidentes em obras. Para mitigar este fator, com base em Saurin (2005) podem ser tomadas precauções como as listadas no Quadro 5. 


\section{RECIMA21 - REVISTA CIENTÍFICA MULTIDISCIPLINAR ISSN 2675-6218}

INFLUÊNCIA DO PROJETO ARQUITETÔNICO NA SEGURANÇA DO TRABALHO: PREVENÇÃO DE ACIDENTES EM OBRAS Karine Lopes Ferreira, Bruno Márcio Agostini

Quadro 5 - Ações e justificativas - Quedas (continua)

\begin{tabular}{|c|c|c|}
\hline ITEM & AÇÃO NA FASE DE PROJETO & JUSTIFICATIVAS \\
\hline 1 & $\begin{array}{l}\text { Esperas para escada ou escada permanente } \\
\text { incorporada ao prédio (externamente). }\end{array}$ & $\begin{array}{l}\text { Acesso ao telhado para execução da } \\
\text { cobertura/telhamento e manutenção. }\end{array}$ \\
\hline 2 & $\begin{array}{l}\text { Desenvolver mecanismo para trocar lâmpadas em } \\
\text { áreas com pé-direito alto. }\end{array}$ & $\begin{array}{l}\text { Viabilizar trocas seguras de lâmpadas } \\
\text { em áreas críticas. }\end{array}$ \\
\hline 3 & $\begin{array}{l}\text { Escada incorporada à estrutura para acesso a } \\
\text { janelas altas }(>2,0 \mathrm{~m}) \text {. }\end{array}$ & $\begin{array}{l}\text { Viabilizar acesso seguro a essas } \\
\text { janelas em operações de manutenção. }\end{array}$ \\
\hline 4 & $\begin{array}{l}\text { Prever esperas para escada de mão ou incorporar } \\
\text { escada permanente para acesso a telhados, } \\
\text { visando manutenção. Para impedir o uso da } \\
\text { escada por pessoal não autorizado, sua parte } \\
\text { inferior pode ser destacável ou cercada e com } \\
\text { fechadura. }\end{array}$ & $\begin{array}{l}\text { Evitar improvisos no acesso a } \\
\text { telhados. }\end{array}$ \\
\hline 5 & $\begin{array}{l}\text { Prever alçapões de acesso a telhados com } \\
\text { dimensões que permitam a passagem de uma } \\
\text { pessoa (no mínimo } 60 \mathrm{~cm} \times 60 \mathrm{~cm} \text { ). }\end{array}$ & $\begin{array}{l}\text { Viabilizar acesso ao interior de } \\
\text { telhados. }\end{array}$ \\
\hline 6 & $\begin{array}{l}\text { Localizar alçapões de acesso distantes da periferia } \\
\text { da estrutura. }\end{array}$ & $\begin{array}{l}\text { Viabilizar acesso ao interior de } \\
\text { telhados. }\end{array}$ \\
\hline 7 & $\begin{array}{l}\text { Todas as platibandas, sacadas, parapeitos de } \\
\text { janelas e outros locais similares com perigo de } \\
\text { queda devem possuir a altura mínima de guarda- } \\
\text { corpos exigida pela NR-18 (BRASIL, 2020b), item } \\
8.9(1,20 \mathrm{~m}) \text {. }\end{array}$ & $\begin{array}{l}\text { Evitar a colocação de proteção } \\
\text { complementar para prevenção de } \\
\text { quedas. }\end{array}$ \\
\hline 8 & $\begin{array}{l}\text { Especificar telhas com capacidade de carga para } \\
\text { suportar uma pessoa caminhando sobre a mesma, } \\
\text { ou projetar passarela para circulação sobre as } \\
\text { telhas. }\end{array}$ & $\begin{array}{l}\text { Evitar colapso das telhas em caso de } \\
\text { circulação sobre as mesmas. }\end{array}$ \\
\hline 9 & Minimizar a inclinação dos telhados. & $\begin{array}{l}\text { Reduzir probabilidade de } \\
\text { escorregamento de pessoas e } \\
\text { materiais. }\end{array}$ \\
\hline 10 & $\begin{array}{l}\text { Projetar meios para que janelas em andares altos } \\
\text { possam ser limpas por dentro da edificação. Por } \\
\text { exemplo, especificar janelas tipo maxim-ar que } \\
\text { permitam giro de } 90^{\circ} \text { ou janelas que possam ser } \\
\text { retiradas para limpeza. }\end{array}$ & Prevenir quedas de altura. \\
\hline
\end{tabular}




\section{RECIMA21 - REVISTA CIENTÍFICA MULTIDISCIPLINAR} ISSN 2675-6218

INFLUÊNCIA DO PROJETO ARQUITETÔNICO NA SEGURANÇA DO TRABALHO: PREVENÇÃO DE ACIDENTES EM OBRAS Karine Lopes Ferreira, Bruno Márcio Agostini

Quadro 5 - Ações e justificativas - Quedas (conclusão)

\begin{tabular}{|c|c|c|}
\hline 11 & $\begin{array}{l}\text { Em caso de haver passarelas ou saliências junto à } \\
\text { fachada, prever ponto de ancoragem para fixar } \\
\text { equipamento de trabalho ou EPI - item } 18.12 .12 \\
\text { (BRASIL, 2020b). }\end{array}$ & $\begin{array}{l}\text { Facilitar uso de cinto de segurança } \\
\text { caso a passarela ou saliência seja } \\
\text { usada para acesso em serviços de } \\
\text { manutenção. }\end{array}$ \\
\hline 12 & $\begin{array}{l}\text { Prever meios para limpeza interna de telhados } \\
\text { envidraçados. Por exemplo, em coberturas zenitais, } \\
\text { planejar plataformas móveis, internas ao prédio, } \\
\text { para facilitar atividades de manutenção. }\end{array}$ & $\begin{array}{l}\text { Viabilizar manutenção segura da parte } \\
\text { interna de telhados envidraçados. }\end{array}$ \\
\hline 13 & $\begin{array}{l}\text { Projetar meios para limpeza e manutenção externa } \\
\text { de telhados. Por exemplo, prever linhas de cabo- } \\
\text { guia (transversais e longitudinais) para circulação } \\
\text { sobre telhado. }\end{array}$ & $\begin{array}{l}\text { Facilitar circulação segura sobre } 0 \\
\text { telhado. }\end{array}$ \\
\hline 14 & $\begin{array}{l}\text { Evitar especificação de revestimentos cerâmicos } \\
\text { externos nas platibandas. }\end{array}$ & $\begin{array}{l}\text { Dificuldades de acesso à platibanda } \\
\text { para instalação das peças cerâmicas. }\end{array}$ \\
\hline 15 & $\begin{array}{l}\text { Evitar degraus e depressões próximos a janelas e } \\
\text { aberturas no piso. }\end{array}$ & Evitar quedas de altura. \\
\hline 16 & $\begin{array}{l}\text { Evitar projeto de volumes de fachada com largura } \\
\text { menor que } 1,0 \mathrm{~m} .\end{array}$ & $\begin{array}{l}\text { Dificuldade de instalação de andaimes } \\
\text { suspensos para serviços de } \\
\text { revestimento, levando a improvisos. }\end{array}$ \\
\hline 17 & $\begin{array}{l}\text { Projetar floreiras que possuam acesso direto a } \\
\text { partir de janela logo em frente, ou projetar escada } \\
\text { externa de acesso às floreiras. }\end{array}$ & $\begin{array}{l}\text { Prevenir quedas de altura no acesso à } \\
\text { floreira. }\end{array}$ \\
\hline 18 & $\begin{array}{l}\text { Não projetar rampas que mudem de inclinação } \\
\text { repentinamente sem aviso. É aconselhável a } \\
\text { colocação de um guarda-corpo acompanhando a } \\
\text { inclinação da rampa. }\end{array}$ & Evitar quedas e tropeções. \\
\hline
\end{tabular}

Fonte: adaptado de Saurin (2005)

Relacionado ao tipo de escada citado nos itens 1, 3, 4 e 17 do Quadro 5 tem-se o item 18.8.6 da NR-18 (BRASIL, 2020b). Nesse item são abordadas as medidas a serem adotadas para garantir a segurança em escadas, entre elas, a escada fixa vertical. Esse tipo de escada deve possuir largura prevista entre $0,40 \mathrm{~m}$ e $0,60 \mathrm{~m}$; corrimão ou continuação dos montantes da escada ultrapassando a plataforma de descanso ou o piso superior; plataformas de descanso se for múltiplos lances; espaçamento uniforme entre os degraus; fixação na base; entre outros requisitos; além da obrigatoriedade de possuir Sistema de Proteção Individual Contra Quedas (SPIQ) para escadas desse tipo com altura superior a 2m (BRASIL, 2020b).

Complementar ao item 7 do Quadro 5 acima, em que foi citada a altura mínima de 1,2m como medida de prevenção contra queda em altura apresentada no item 18.9 da NR-18 (BRASIL, 2020b), 


\section{RECIMA21 - REVISTA CIENTÍFICA MULTIDISCIPLINAR ISSN 2675-6218}

INFLUÊNCIA DO PROJETO ARQUITETÔNICO NA SEGURANÇA DO TRABALHO: PREVENÇÃO DE ACIDENTES EM OBRAS Karine Lopes Ferreira, Bruno Márcio Agostini

há também o item 18.8.6.2 da mesma norma, que trata de escada fixa vertical, já citada no parágrafo anterior. Neste caso, a norma aponta necessidade de altura entre $1,1 \mathrm{~m}$ a $1,2 \mathrm{~m}$ para corrimãos ou continuação dos montantes da escada ultrapassando a plataforma de descanso ou o piso superior. Essa mesma altura, 1,2m, deve ser utilizada para a constituição de anteparos rígidos que previnam quedas em vãos no piso (BRASIL, 2020b).

Ainda sobre a altura de corrimãos, tem-se a versão revisada da norma ABNT NBR 14718/2019: Esquadrias - Guarda-corpos para edificação - Requisitos, procedimentos e métodos de ensaio, que é aplicável a ambientes externos ou internos de edificações privativas ou coletivas que sejam habitacionais, comerciais, industriais, esportivas, culturais, religiosas, turísticas, educacionais, de saúde e de terminais de passageiros (CBIC, 2019). A ABNT NBR 14718/2019 consta inclusive nas referências bibliográficas da Instrução Técnica (IT) 08 do Corpo de Bombeiros de Minas Gerais (CBMMG, 2021), que aborda as saídas de emergência em edificações, no entanto, esta IT traz 1,3m como mínimo para acessos a escada enclausuradas e escadas abertas externas. Sendo assim é possível perceber que um mesmo item é abordado em normativas e instruções diferentes, fazendo-se necessário que os profissionais ligados ao projeto estejam sempre atentos às finalidades que o projeto pretende atender e quais normas devem ser seguidas.

Sobre os itens 8 e 9 do Quadro 5, que abordam telhados, tem-se ainda a recomendação da NR-18 (BRASIL, 2020b), item 18.7.8.1 em que se pede a aplicação do disposto na NR-35 para telhados e coberturas que excedam $2 \mathrm{~m}$ de altura e risco de quedas de pessoas. Já o item 18.7.8.1.1 da NR-18 (BRASIL, 2020b) traz que o acesso ao SPIQ instalado sobre telhados e coberturas deve ser projetado de forma a não oferecer risco de quedas.

Abordando de forma geral o risco de queda em altura, o item 18.9 da NR-18 (BRASIL, 2020b) traz requisitos a serem atendidos, como:

- 18.9.1: obrigatoriedade de instalação de proteção coletiva onde houver risco de queda ou de projeção de materiais e objetos no entorno da obra, e deve ser projetada por profissional legalmente habilitado;

- 18.9.2: aberturas no piso devem ter fechamento provisório; adoção de sistema de proteção contra quedas; entre outros.

\subsubsection{UTILIZAÇÃO INADEQUADA DE EQUIPAMENTOS E APARELHOS}

Essa questão pode ser solucionada através da elaboração do projeto executivo e detalhamentos por meio de um levantamento dos materiais necessários à execução da obra e a partir de então, selecionar profissionais que atendam as demandas de capacitação para cada instrumento, assim como seguir os dispostos no item 18.10 da NR-18 (BRASIL, 2020b) e a NR-12 (BRASIL, 2019c) Segurança do Trabalho em Máquinas e Equipamentos.

\subsubsection{IMPACTO DE OBJETOS}

Sobre impacto de objetos, o Quadro 6 a seguir destaca alguns pontos que devem ser considerados no projeto, com base em Saurin (2005):

RECIMA21 - Ciências Exatas e da Terra, Sociais, da Saúde, Humanas e Engenharia/Tecnologia 


\section{RECIMA21 - REVISTA CIENTÍFICA MULTIDISCIPLINAR ISSN 2675-6218}

INFLUÊNCIA DO PROJETO ARQUITETÔNICO NA SEGURANÇA DO TRABALHO: PREVENÇÃO DE ACIDENTES EM OBRAS Karine Lopes Ferreira, Bruno Márcio Agostini

Quadro 6 - Ações e justificativas - Impacto de objetos

\begin{tabular}{|c|l|l|}
\hline ITEM & \multicolumn{1}{|c|}{ AÇÃO NA FASE DE PROJETO } & \multicolumn{1}{c|}{ JUSTIFICATIVAS } \\
\hline 1 & $\begin{array}{l}\text { Evitar colocar portas ou janelas envidraçadas em } \\
\text { frente a lance de escadas. }\end{array}$ & $\begin{array}{l}\text { Minimizar efeitos de impactos contra } \\
\text { portas ou janelas. }\end{array}$ \\
\hline 2 & $\begin{array}{l}\text { Locar escadas e rampas de modo que se situem } \\
\text { paralelas e adjacentes ao edifício, ao invés de } \\
\text { perpendicularmente à estrutura. }\end{array}$ & $\begin{array}{l}\text { Evitar a criação de passarelas onde } \\
\text { possa haver perigo de queda de } \\
\text { materiais sobre pedestres passando } \\
\text { abaixo. }\end{array}$ \\
\hline 3 & $\begin{array}{l}\text { Projetar extremidades de corrimãos acabando em } \\
\text { curva, ao invés de ponta - item 5.8.2.5, IT 08 } \\
\text { (CBMMG, 2021). }\end{array}$ & $\begin{array}{l}\text { Evitar enganchamentos de roupas e } \\
\text { minimizar efeitos de impactos contra } \\
\text { o corrimão. }\end{array}$ \\
\hline 4 & $\begin{array}{l}\text { Projetar rotas de pedestres de modo que se situem } \\
\text { um pouco afastadas da fachada. }\end{array}$ & $\begin{array}{l}\text { Evitar que pessoas batam a cabeça } \\
\text { em janelas ou portas abertas. }\end{array}$ \\
\hline 5 & $\begin{array}{l}\text { Projetar pisos ao redor de equipamentos mecânicos } \\
\text { com um único nível. }\end{array}$ & $\begin{array}{l}\text { Evitar tropeções e impacto contra os } \\
\text { equipamentos. }\end{array}$ \\
\hline
\end{tabular}

Fonte: adaptado de Saurin (2005)

Sobre o item 3 indicado no Quadro 6, esta é inclusive uma exigência do Corpo de Bombeiros de Minas Gerais para as saídas de emergência. Está expresso na IT 08 (CBMMG, 2021), através do item 5.8.2.5 em que não se aceitam corrimãos construídos por elementos com arestas vivas, tábuas largas na horizontal e outros (CBMMG, 2020). Claramente, corrimãos com arestas vivas e/ou pontas representam riscos de acidentes e ferimentos não apenas durante a execução da obra, mas também posteriormente em sua utilização e manutenção.

\subsubsection{CONDIÇÕES INADEQUADAS DOS AMBIENTES}

Com relação às condições inadequadas do ambiente de trabalho, como desorganização do canteiro de obras, no Quadro 7 são apontadas algumas recomendações segundo Basto, Vasconcelos e Bardokébas (2016). Com base nesses autores, essas medidas são importantes porque quando se realiza previamente a separação das etapas necessárias na obra, entendendo seus objetivos, elementos e processos de elaboração, fica mais fácil antever os riscos que poderiam levar a acidentes e tomar as devidas providências. 


\section{RECIMA21 - REVISTA CIENTÍFICA MULTIDISCIPLINAR ISSN 2675-6218}

INFLUÊNCIA DO PROJETO ARQUITETÔNICO NA SEGURANÇA DO TRABALHO: PREVENÇÃO DE ACIDENTES EM OBRAS Karine Lopes Ferreira, Bruno Márcio Agostini

Quadro 7 - Ações e justificativas - Condições inadequadas do ambiente de trabalho (continua)

\begin{tabular}{|c|c|c|}
\hline ITEM & AÇÃO NA FASE DE PROJETO & JUSTIFICATIVAS \\
\hline 1 & $\begin{array}{l}\text { Além de retratar o produto no projeto, fazer } \\
\text { também um projeto para execução deste, onde } \\
\text { serão especificados materiais e sistemas menos } \\
\text { perigosos. }\end{array}$ & $\begin{array}{l}\text { Evitar improvisos e escolhas } \\
\text { inseguras de equipamentos e } \\
\text { sistemas inadequados durante a } \\
\text { obra. }\end{array}$ \\
\hline
\end{tabular}

Quadro 7 - Ações e justificativas - Condições inadequadas do ambiente de trabalho (conclusão)

\begin{tabular}{|c|l|lrl|}
\hline 2 & $\begin{array}{l}\text { Definir os procedimentos e sequências de trabalho, } \\
\text { recursos e componentes necessários. }\end{array}$ & $\begin{array}{l}\text { Diminuir os riscos em } \\
\text { consequência da diminuição de } \\
\text { improvisos. }\end{array}$ \\
\hline
\end{tabular}

Fonte: adaptado de Basto, Vasconcelos e Bardokebas, (2016)

\subsubsection{FALTA DE DISPOSITIVO DE PROTEÇÃO PARA ACESSO À OBRA E UTILIZAÇÃO DO MESMO MEIO DE TRANSPORTE PARA PESSOAS E CARGAS}

Sobre a falta de dispositivos de proteção para acesso a obra, devem ser previstas medidas de controle, incluindo as medidas administrativas, para que apenas pessoas autorizadas e com EPI necessário acessem a obra. Deve haver também sinalização adequada, e além disso, Saurin (2005) também abordou, conforme o item 1 do Quadro 8, cuidado para evitar atropelamentos.

Sobre a utilização do mesmo meio de transporte utilizado para pessoas e cargas, também abordado no Quadro 8 (item 2), tem-se as considerações da NR-18 (BRASIL, 2020b) que faz as devidas recomendações sobre esse assunto no item 18.11 Movimentação e Transporte de Materiais e Pessoas. De acordo com o tópico 18.11.17: é proibido, nos elevadores, o transporte de pessoas juntamente com materiais, exceto quanto ao operador e ao responsável pelo material a ser transportado, desde que isolados da carga por uma barreira física, com altura mínima de 1,8 m (um metro e oitenta centímetros), instalada com dispositivo de intertravamento com duplo canal e ruptura positiva, monitorado por interface de segurança (BRASIL, 2020b).

De acordo com a mesma norma, os elevadores que realizam a movimentação e transporte de pessoas e cargas devem ser dimensionados por profissionais legalmente habilitados e atender todas as demandas normativas existentes. 


\section{RECIMA21 - REVISTA CIENTÍFICA MULTIDISCIPLINAR ISSN 2675-6218}

INFLUÊNCIA DO PROJETO ARQUITETÔNICO NA SEGURANÇA DO TRABALHO: PREVENÇÃo DE ACIDENTES EM OBRAS Karine Lopes Ferreira, Bruno Márcio Agostini

Quadro 8 - Ações e justificativas - Falta de dispositivo ao acesso à obra e utilização do mesmo meio de transporte para pessoas e cargas

\begin{tabular}{|c|l|l|}
\hline ITEM & \multicolumn{1}{|c|}{ AÇÃO NA FASE DE PROJETO } & \multicolumn{1}{|c|}{ JUSTIFICATIVA } \\
\hline 1 & $\begin{array}{l}\text { Evitar saídas de estacionamento cegas, onde } \\
\text { motorista do veículo e pedestre não visualizam um } \\
\text { ao outro. }\end{array}$ & Evitar atropelamentos. \\
\hline 2 & $\begin{array}{l}\text { Não utilizar o mesmo meio de transporte para } \\
\text { pessoas e cargas. }\end{array}$ & $\begin{array}{l}\text { Evitar acidentes com impacto por } \\
\text { objetos. }\end{array}$ \\
\hline
\end{tabular}

Fonte: adaptado de Saurin, (2005); e NR-18, (2020b)

\subsubsection{USO INADEQUADO DO EPI}

O uso inadequado do EPI pode ser solucionado através do entrosamento dos profissionais de projeto com os de segurança. A partir da definição do projeto podem ser dimensionados quantos trabalhadores necessários, suas frentes de trabalho e suas respectivas necessidades e a partir de então podem ser realizadas instruções e treinamentos com os profissionais da obra.

Além disso, será exigência do item 18.4.3 da NR-18 (BRASIL, 2020b) - que entrará em vigor em janeiro de 2022 - que conste no PGR a relação dos EPI necessários e suas respectivas especificações técnicas de acordo com os riscos ocupacionais existentes (BRASIL, 2020b). Além disso, o uso adequado do EPI fará parte do conteúdo programático do treinamento inicial proposto pela NR-18, conforme alínea a, item 4 do Anexo I (BRASIL, 2020b).

\subsubsection{DEMANDA EM EXCESSO AOS TRABALHADORES}

Com o projeto, devidos detalhamentos e cronograma de execução em mãos é possível evitar que os profissionais sejam submetidos a sobrecarga, uma vez que facilita o dimensionamento adequado do número de profissionais para atender cada demanda de acordo com seu nível de complexidade e cronograma.

Ainda sobre as demandas em excesso que acometem os trabalhadores e atividades que exijam esforço físico em demasia, os autores Basto, Vasconcelos e Bardokébas (2016) apresentaram os apontamentos dos itens 1 e 2 do Quadro 9. O autor Smallwood (2005) também traz sua contribuição com o item 3 do Quadro 9. 


\section{RECIMA21 - REVISTA CIENTÍFICA MULTIDISCIPLINAR} ISSN 2675-6218

INFLUÊNCIA DO PROJETO ARQUITETÔNICO NA SEGURANÇA DO TRABALHO: PREVENÇÃO DE ACIDENTES EM OBRAS Karine Lopes Ferreira, Bruno Márcio Agostini

Quadro 9 - Ações e justificativas - Demanda em excesso aos trabalhadores

\begin{tabular}{|c|c|c|}
\hline ITEM & AÇÃO NA FASE DE PROJETO & JUSTIFICATIVAS \\
\hline 1 & Destinar o tempo necessário adequado ao projeto. & $\begin{array}{l}\text { Para que seja realizado com a } \\
\text { devida atenção e detalhamentos } \\
\text { necessários, abarcando a SST } \\
\text { desde seu início. }\end{array}$ \\
\hline 2 & $\begin{array}{l}\text { Utilizar materiais didáticos que sejam seus auxiliares } \\
\text { na fase do projeto, como softwares que } \\
\text { recomendem diretrizes a serem seguidas em cada } \\
\text { etapa e tipologia projetada. }\end{array}$ & Podem otimizar o trabalho. \\
\hline 3 & $\begin{array}{l}\text { Não incluir elementos que exijam procedimentos ou } \\
\text { materiais perigosos, como por exemplo materiais } \\
\text { pesados que ocasionam problemas de manuseio ou } \\
\text { que exijam métodos de fixação desconfortáveis para } \\
\text { os trabalhadores. }\end{array}$ & $\begin{array}{l}\text { Evitar que os funcionários trabalhem } \\
\text { em posições desconfortáveis, com } \\
\text { movimentos repetitivos e/ou usem } \\
\text { demasiadamente a força corporal }\end{array}$ \\
\hline
\end{tabular}

Fonte: adaptado de Basto, Vasconcelos e Bardokébas, (2016); e Smallwood, (2005)

Além das recomendações do Quadro 9, cabe citar também a NR-17 - Ergonomia (BRASIL, 2018b), que pode guiar quais posições/tipos de serviços podem ser prejudiciais à saúde do trabalhador.

Cabe ressaltar que este trabalho não pretende ser exaustivo quanto aos tópicos de verificação apresentados ao longo da presente seção, e, a depender da especificidade do projeto, podem ser identificados outros itens que também requeiram atenção, sendo assim, o material apresentado pode e deve ser constantemente aperfeiçoado. Nesse sentido é necessário salientar a importância de sempre deixar documentadas as novas considerações identificadas, a fim de que não sejam perdidos os conhecimentos e experiências obtidos. Ressalta-se também que os aspectos apresentados nos quadros cinco a nove são relativos ao projeto arquitetônico e suas respectivas justificativas, objetivando o não esquecimento de quesitos que demandam atenção. $O$ mesmo pode ser feito para os outros projetos como o estrutural, de instalações, entre outros.

\section{CONSIDERAÇÕES FINAIS}

Foi apresentado ao longo do trabalho o potencial que o projeto arquitetônico tem de reduzir acidentes no canteiro de obras e posteriormente na fase de manutenção, e que para isso é imprescindível a conscientização do profissional responsável pelo projeto arquitetônico quanto a essa necessidade de abordagem da segurança. A introdução de matérias com essa temática nas grades curriculares das universidades seria um grande avanço nesse sentido, mas de forma mais imediata, pode-se citar como alternativa a realização de consultorias com profissionais experientes em gestão de segurança no canteiro de obras.

Também foram apresentadas possíveis questões a serem avaliadas durante a elaboração do projeto arquitetônico, e que podem originar listas de verificação ou outras ferramentas às quais os

RECIMA21 - Ciências Exatas e da Terra, Sociais, da Saúde, Humanas e Engenharia/Tecnologia 


\section{RECIMA21 - REVISTA CIENTÍFICA MULTIDISCIPLINAR} ISSN 2675-6218

INFLUÊNCIA DO PROJETO ARQUITETÔNICO NA SEGURANÇA DO TRABALHO: PREVENÇÃO DE ACIDENTES EM OBRAS Karine Lopes Ferreira, Bruno Márcio Agostini

projetistas se adaptem. Esse tipo de conduta pode também ser replicado para os outros projetos, como elétrico, hidráulico, estrutural, entre outros.

A ideia da PAP vem da necessidade de minimizar os riscos existentes na construção civil, trabalhando com a antecipação de possíveis ocorrências no canteiro de obras evitando que o trabalhador seja exposto ao risco. No presente trabalho foi demonstrado que além de ser necessária, essa abordagem é factível e, ao longo da elaboração do projeto arquitetônico é o momento ideal para buscar identificar perigos e riscos apresentando soluções projetuais que podem impactar positivamente durante a execução e até manutenção.

Dessa forma, a aplicação da PAP se dá através do desenvolvimento do projeto com foco no trabalhador que executará o projeto, considerando também as futuras manutenções que ocorrerão na edificação, o que reforça a necessidade de uma postura preventiva pelo projetista para que cada vez mais a segurança seja vista como algo indissociável do exercício de projeto.

É válido ressaltar também a importância de sempre estar acompanhando as atualizações das normas regulamentadoras e demais normas pertinentes à construção civil, principalmente a NR-17 (BRASIL, 2018b), que trata de Ergonomia, a NR-18 (BRASIL, 2020b) que aborda a Segurança e Saúde do Trabalho na Indústria da Construção e a NR-35 (BRASIL, 2019c), que trata do Trabalho em Altura. Especial atenção deve ser dada a essa última norma, em razão da constatação perante os trabalhos analisados que as quedas estão entre as principais causas de acidentes na construção civil.

\section{REFERÊNCIAS}

ANAMT - Associação Nacional de Medicina do Trabalho. Construção civil está entre os setores com maior risco de acidentes de trabalho. Rio de Janeiro: ANAMT, 2019. Disponível em: https://www.anamt.org.br/portal/2019/04/30/construcao-civil-esta-entre-os-setores-com-maior-riscode-acidentes-de-trabalho/. Acesso em: 30 mar. 2020.

BASTO, P.; VASCONCELOS, B.; BARDOKÉBAS, B. Análise das causas de acidentes de trabalho ocorridos numa obra e possíveis relações com Projeto. Revista de Engenharia e Pesquisa Aplicada, $\quad$ v. 2, n. $1, \quad 8$ nov. 2016. Disponível em: http://revistas.poli.br/index.php/repa/article/view/347/95. Acesso em: 22 jun. 2020.

BRASIL. Ministério da Economia. Comunicação de Acidente de Trabalho - CAT. Brasília: Ministério da Economia, 2021. Disponível em: https://www.gov.br/inss/pt-br/saibamais/auxilios/comunicacao-de-acidente-de-trabalho-cat. Acesso em: 26 ago. 2021.

BRASIL. Ministério da Economia. Anuário Estatístico de Acidentes do Trabalho. Brasília: Ministério da Economia, 2020a. Disponível em: http://www.previdencia.gov.br/dados-abertos/dadosabertos-sst/. Acesso em: 26 mar. 2020.

BRASIL. Ministério do Trabalho e Previdência. NR 5 - Comissão interna de prevenção de acidentes - CIPA. Brasília: Ministério do Trabalho e Previdência, 2019. Disponível em: https://www.gov.br/trabalho/pt-br/inspecao/seguranca-e-saude-no-trabalho/normasregulamentadoras/nr-05.pdf. Acesso em: 10 ago. 2021.

BRASIL. Ministério do Trabalho e Previdência. NR 7 - Programa de controle médico de saúde ocupacional. Brasília: Ministério do Trabalho e Previdência, 2018. Disponível em: 


\section{RECIMA21 - REVISTA CIENTÍFICA MULTIDISCIPLINAR} ISSN 2675-6218

INFLUÊNCIA DO PROJETO ARQUITETÔNICO NA SEGURANÇA DO TRABALHO: PREVENÇÃO DE ACIDENTES EM OBRAS Karine Lopes Ferreira, Bruno Márcio Agostini

https://www.gov.br/trabalho/pt-br/inspecao/seguranca-e-saude-no-trabalho/normasregulamentadoras/nr-07.pdf. Acesso em: 10 ago. 2021.

BRASIL. Ministério do Trabalho e Previdência. NR 9 - Programa de Prevenção de Riscos Ambientais. Brasília: Ministério do Trabalho e Previdência, 2019b. Disponível em: https://www.gov.br/trabalho-e-previdencia/pt-br/composicao/orgaos-especificos/secretaria-detrabalho/inspecao/seguranca-e-saude-no-trabalho/normas-regulamentadoras/nr-09-atualizada2019.pdf. Acesso em: 29 ago. 2021.

BRASIL. Ministério do Trabalho e Previdência. NR 12 - Segurança no trabalho em máquinas e equipamentos. Brasília: Ministério do Trabalho e Previdência, 2019c. Disponível em: https://www.gov.br/trabalho/pt-br/inspecao/seguranca-e-saude-no-trabalho/normasregulamentadoras/nr-12.pdf. Acesso em: 10 ago. 2021.

BRASIL. Ministério do Trabalho e Previdência. NR 17 - Ergonomia. Brasília: Ministério do Trabalho e Previdência, 2018b. Disponível em: https://www.gov.br/trabalho/pt-br/inspecao/seguranca-e-saudeno-trabalho/normas-regulamentadoras/nr-17.pdf. Acesso em: 10 ago. 2021.

BRASIL. Escola Nacional de Inspeção do Trabalho. NR 18 - Condições e Meio ambiente de Trabalho na Indústria da Construção. Brasília: Secretaria Especial de Previdência e Trabalho do Ministério da Economia, 2018c. Disponível em: https://www.gov.br/trabalho-e-previdencia/ptbr/composicao/orgaos-especificos/secretaria-de-trabalho/inspecao/seguranca-e-saude-notrabalho/normas-regulamentadoras/nr-18.pdf. Acesso em: 29 ago. 2020.

BRASIL. Escola Nacional de Inspeção do Trabalho. NR 18 - Condições de Segurança e Saúde no Trabalho na Indústria da Construção. Brasília: Secretaria Especial de Previdência e Trabalho do Ministério da Economia, 2020b. Disponível em: https://enit.trabalho.gov.br/portal/index.php/seguranca-e-saude-no-trabalho/sst-menu/sstnormatizacao/sst-nr-portugues?view=default. Acesso em: 30 out. 2020.

BRASIL. Ministério do Trabalho e Previdência. NR 35 - Trabalho em altura. Brasília: Ministério do Trabalho e Previdência, 2019c. Disponível em: https://www.gov.br/trabalho/pt-br/inspecao/segurancae-saude-no-trabalho/normas-regulamentadoras/nr-35.pdf. Acesso em: 10 ago. 2021.

BRASIL. Trabalho, Emprego e Previdência. Registrar Comunicação de Acidente de Trabalho CAT. Brasilia: Trabalho, Emprego e Previdência, 2021b. Disponível em: https://www.gov.br/ptbr/servicos/registrar-comunicacao-de-acidente-de-trabalho-cat. Acesso em: 26 ago. 2021.

CARVALHO, D. Acidentes na Construção Civil - Uma infeliz realidade do setor. Sienge Plataforma, 2017. Disponível em: https://www.sienge.com.br/blog/acidentes-na-construcao-civil/. Acesso em: 26 ago. 2021.

CBMMG - CORPO DE BOMBEIROS MILITAR DE MINAS GERAIS. Instrução Técnica no 8/2020: Saídas de emergência em edificações. Minas Gerais: Diário Oficial do Estado de Minas Gerais, $2021 . \quad$ Disponível em: https://www.bombeiros.mg.gov.br/storage/files/shares/intrucoestecnicas/IT 08 2a Ed portaria $63 \mathrm{er}$ rata 04.pdf. Acesso em: 21 jul. 2021.

CBIC - CÂMARA BRASILEIRA DA INDÚSTRIA DA CONSTRUÇÃO. Publicada revisão da norma de Guarda-corpos para edificação. Brasília: CBIC, 2019. Disponível em: https://cbic.org.br/inovacao/2019/09/06/publicada-revisao-da-norma-de-guarda-corpos-paraedificacao-3/. Acesso em: 24 mar. 2021.

CUSTÓDIO, D.; SCHORR, M. Acidentes de trabalho na indústria da construção: estatísticas extraídas dos anexos I e II da NR-18. In: Anais... Seminário nacional estatísticas sobre doenças e acidentes de trabalho no Brasil: situação e perspectivas. São Paulo: PRODAT - FUNDACENTRO, 2000. 


\section{RECIMA21 - REVISTA CIENTÍFICA MULTIDISCIPLINAR} ISSN 2675-6218

INFLUÊNCIA DO PROJETO ARQUITETÔNICO NA SEGURANÇA DO TRABALHO: PREVENÇÃO DE ACIDENTES EM OBRAS Karine Lopes Ferreira, Bruno Márcio Agostini

MANU, P. et al. The health and safety impact of construction project features. Engineering, Construction and Architectural Management, v. 21, n. 1. p. 65-93, jan. 2014. Disponível em: https://uwe-repository.worktribe.com/output/822506. Acesso em: 30 mar. 2020.

MAZON, C. N.; SAVI, C. N. Análise de acidentes de trabalho na construção civil de Criciúma/SC no período de 2012 e 2013 - estudo de caso. TCC (Graduação em Engenharia Civil) - Faculdade de Engenharia Civil, Centro Universitário do Espírito Santo, Espírito Santo. 2013. Disponível em: http://repositorio.unesc.net/handle/1/2468. Acesso em: 25 mar. 2021.

NIOSH - National Institute for Occupational Safety and Health. Prevention through Design. [S. I.]: Niosh, 2013. Disponível em: http://www.cdc.gov/niosh/topics/ptd/. Acesso em: 06 maio 2020.

RAMOS, É. Número de acidentes de trabalho no Brasil e no RS segue alto. Porto Alegre: Justiça do Trabalho TRT da 4⿳亠丷厂 Região (RS), 2020. Disponível em: https://tecnoblog.net/247956/referenciasite-abnt-artigos/. Acesso em: 31 ago. 2020.

SAURIN, T. A. Segurança no trabalho e desenvolvimento de produto: diretrizes para integração na construção civil. Prod., São Paulo, v. 15, n. 1, p. 127-141, abr. 2005. Disponível em http://www.scielo.br/scielo.php?script=sci arttext\&pid=S0103-65132005000100011\&lng=pt\&nrm=iso.

Acesso em: 17 jul. 2020.

SILVA, B. M. V. Segurança do trabalho no projeto de arquitetura: diretrizes para o controle dos riscos de acidentes na fase pós-obra. 2009. 126 f. Dissertação (Mestrado em Construção Civil) Universidade de Pernambuco, Recife, PE, 2009. Disponível em: http://livros01.livrosgratis.com.br/cp128485.pdf. Acesso em: 18 abr. 2020.

SILVEIRA, C. A. et al. Acidentes de trabalho na construção civil identificados através de prontuários hospitalares. Rem: Rev. Esc. Minas, Ouro Preto, v. 58, n. 1, p. 39-44, mar. 2005. Disponível em: http://www.scielo.br/scielo.php?script=sci arttext\&pid=S0370-44672005000100007\&lng=en\&nrm=iso. Acesso em: 02 jun. 2020.

SMALLWOOD, J. The need for the inclusion of construction health and safety (h\&s) in architectural education. Research Gate, jan. 2005. Disponível em: https://www.researchgate.net/publication/265873478 THE NEED FOR THE INCLUSION OF CON STRUCTION HEALTH AND SAFETY HS IN ARCHITECTURAL EDUCATION. Acesso em: 03 abr. 2020.

SOUSA, D. R.; CAMPOS, V. R. Análise das principais causas dos acidentes de trabalho no setor da construção civil. In: Congresso Brasileiro de Engenharia de Produção, 7., 2017, Ponta Grossa. Anais... eletrônicos. Ponta Grossa: Aprepro, 2017. Disponível em: https://docplayer.com.br/65013371-Analise-das-principais-causas-dos-acidentes-de-trabalho-no-setorda-construcao-civil.html. Acesso em: 22 abr. 2020.

YOGUI, R. Construtibilidade \& 4D. Apresentação de slides. Rio de Janeiro: PUC, [s.d.]. Disponível em: https://webserver2.tecgraf.puc-rio.br/ftp pub/lfm/Construtibilidade\%20\&\%204D-Yogui.pdf. Acesso em: 17 jul. 2020. 